more than a week apart. The lowest value is then used to determine which quartile the person is in. Even this approach may be insufficient to correct for the variability.

There are outstanding laboratory problems with use of hs-CRP. Not all assays produce identical results. No laboratory has the resources to determine its own reference ranges, so transportability of results between assays is obviously of great importance in defining the concentrations that relate to the different quartiles of basal CRP concentration. At the present time it appears undesirable to attempt to use hs-CRP in individual risk stratification.

\section{REFERENCES}

1. The Joint European Society of Cardiology/American College of Cardiology Committee. Myocardial infarction redefined - a consensus document of the Joint European Society of Cardiology/American College of Cardiology Committee for the redefinition of myocardial infarction. J Am Coll Cardiol 2000;36:959-69.

2. Schroeder JS, Lamb IH, Hu M. Do patients in whom myocardial infarction has been ruled out have a better prognosis after hospitalization than those surviving infarction? N Engl J Med 1980;303:1-5.

3. Hamm CW, Braunwald E. A classification of unstable angina revisited. Circulation 2000;102:118-22.

4. Pennell JP. Optimizing medical management of patients with pre-endstage renal disease. Am J Med 2001;111:559-68.

5. Chen HH, Burnett JC Jr. The natriuretic peptides in heart failure: diagnostic and therapeutic potentials. Proc Assoc Am Physicians 1999;111:406-16.

6. Ridker PM. High-sensitivity C-reactive protein: potential adjunct for global risk assessment in the primary prevention of cardiovascular disease. Circulation 2001;103:1813-8.
7. Campbell B, Badrick T, Flatman R, Kanowski D. Limited clinical utility of high-sensitivity plasma C-reactive protein assays. Ann Clin Biochem 2002;39:85-8.

\section{FURTHER READING}

Ridker PM, Rifai N, Rose L, Buring JE, Cook NR. Comparison of C-reactive protein and low-density lipoprotein cholesterol levels in the prediction of first cardiovascular events. N Engl J Med 2002;347:1557-65.

Ewald B. B-type natriuretic peptide: a new diagnostic tool for congestive heart failure. Aust Prescr 2003;26:64-5.

\section{Conflict of interest: none declared}

\section{Self-test questions}

The following statements are either true or false (answers on page 95)

5. Ectopic production of cardiac troponins reduces their usefulness in assessing acute coronary syndromes.

6. Measuring high sensitivity $\mathrm{C}$-reactive protein provides an accurate prediction of an individual's risk of cardiovascular disease.

\title{
National Prescribing Service Ltd (NPS) information hotlines
}

NPS operates two hotlines providing health professionals and the community with information about medicines.

\section{Therapeutic Advice and Information Service (TAIS): 1300138677}

For general practitioners, pharmacists and other community-based health professionals

The Therapeutic Advice and Information Service (TAIS) has been in operation for three years and to date has received more than 15000 enquiries. The majority of callers were community pharmacists $(48 \%)$ and general practitioners $(35 \%)$. The most commonly asked questions were about drug interactions, adverse reactions and therapeutic options.

Information is provided by expert drug information specialists. The service operates Australia-wide, Monday to Friday 9am to 7pm (EST) for the cost of a local call.

\section{Medicines Line: 1300888763}

\section{For consumers}

TAIS is complemented by Medicines Line, a medicines information hotline for consumers. Medicines Line was launched in September 2002 and receives approximately 1000 calls every month.

Statistics show that most callers are females aged 24-64; $25 \%$ of callers ask for information on behalf of a child, partner or parent. Questions often reflect what is being reported in the media at the time and are focused on adverse reactions, interactions, and to a lesser extent the mechanisms of action of medicines. Questions are most commonly related to antidepressants, antihypertensives and complementary medicines.

Information is provided by expert drug information specialists. The service operates Australia-wide, Monday to Friday 9am to 6pm (EST) for the cost of a local call. 